\title{
Sub-microcrystalline Al achieved by various procedures of constrained groove pressing: microstructure and mechanical properties
}

\author{
Saeid Shahraki ${ }^{a^{*}}$, Behzad Fallah Ghanbari ${ }^{\mathrm{b}}$ and Hossein Abdollahi ${ }^{\mathrm{a}}$
}

${ }^{a}$ Department of Mechanical Engineering, University of Zabol, Zabol, Iran

${ }^{b}$ Department of Materials and Metallurgical Engineering, Iran university of Science and Technology, Tehran, Iran

\begin{tabular}{l}
\hline A R T I C L EI N F O \\
\hline Article history: \\
Received 14 September 2019 \\
Accepted 25 October 2019 \\
Available online \\
25 October 2019 \\
\hline Keywords: \\
Constrained groove pressing \\
die groove angle \\
Cu covering sheets \\
X-ray diffraction \\
Scanning electron microscopy \\
Mechanical properties
\end{tabular}

\section{Introduction}

Processing by SPD refers to various experimental procedures of metal forming that may be used to impose very high strains on materials leading to exceptional grain refinement. A unique feature of SPD processing is that the high strain is imposed without any significant change in the overall dimensions of the workpiece. Another feature is that the shape is retained by using special tool geometries that prevent free flow of the material (Valiev et al., 2006). The main objective of a SPD process is to produce high strength and lightweight parts, that cannot be obtained through conventional thermo-mechanical processing (Azushima et al., 2008). Ultrafine-grained materials produced in this way have submicrometer grain structures and unique physical and mechanical properties and are generally designated nanoSPD materials (Valiev et al., 2006; Alexander, 2007; Dong et al., 2011). Various SPD techniques exclusively meant for processing ultra-fine grained sheet materials have been put forth (Kumar \& Raghu, 2013). Accumulative roll bonding (ARB) by Saito et al. (1999), constrained groove pressing (CGP) by Shin et al. (2002), repetitive corrugation and straightening (RCS) by Huang et al. (2004) are some of the SPD

* Corresponding author. Tel:+98-54-31232024 E-mail addresses: Saeid.Shahraki@uoz.ac.ir (S. Shahraki)

\begin{abstract}
In this research, acheiving submicrocrystalline structure in commercially pure $\mathrm{Al}$ is investigated using severe plastic deformation (SPD) method named constrained groove pressing (CGP). In order to find a procedure that acts more effective in grain refinement and mechanical properties defined by variables of die groove angle $\left(45^{\circ}\right.$ and $\left.50^{\circ}\right)$ and using $\mathrm{Cu}$ covering sheets at top and down of the specimens instead of rigid die surface as a lubricant. Grain refinement during CGP was investigated by William-hall analysis on X-Ray diffraction pattern and scanning refine the microstructure to an ultra-fine grained (UFG) structure with less than 1 micron grain of applying extra CGP passes in $45^{\circ}$ groove angle die with covering sheets (procedure 2 ), final grain size in procedure B is lesser. Mechanical properties of CGPed samples was investigated by tensile and hardness tests and the results show that at primary passes in all procedures strengthrelated properties increases significantly through a decrease in elongation, but at subsequent passes
\end{abstract} C 2020 Growing Science Ltd. All rights reserved. 
techniques proposed for processing bulk materials in sheet forms. Constrained groove pressing is one of the this SPD methods that uses repeated shearing deformations imposed by asymmetrically grooved and flat dies to accumulate strain, alternatively (Shin et al. 2002). This method is widely used to produce UFG commercially pure Al sheets (Shin et al. 2002; Hosseini \& Kazeminezhad,2009; Borhani et al. 2012; Krishnaiah et al. 2005; Lee et al. 2002; Sajadi et al. 2012; Shirdel et al. 2010; Zrnik et al. 2009) and other sheet metals. Recent studies show that CGP can severely refine microstructure to submicrocrystalline range and consequently improve the mechanical properties like strength and hardness.

Reviewing the presented papers on CGP, clears that most of the previous works on CGP is carried out on a die with groove angle of $45^{\circ}$, and in addition, the maximum number of CGP passes conducted are three or four passes that equals with imposing strain of 4.46 (at groove angle of $45^{\circ}$ ). In this study, Effect of die groove angle on mechanical properties distribution and grain refinement of $\mathrm{Al}$ sheets is investigated, using two dies with different groove angles of $45^{\circ}$ and $50^{\circ}$ at various procedures. In the previous works Teflon sheets (Hosseini \& Kazeminezhad, 2009) and rubber pad (Borhani \& Djavanroodi, 2012) have been used at top and of the specimen instead of rigid die surface, and in this study, $\mathrm{Cu}$ deformable sheets are used as a lubricant. By starting the deformation, $\mathrm{Cu}$ sheets were deformed and flowed in a same direction by Al sheets and led to lowering friction. By this means, surface micro-cracking had postponed and imposing large strain of about 7 through six passes of CGP process is facilitated.

Transmission electron microscopy (TEM) and X-ray diffraction (XRD) are two basic methods for determining the grain size evaluation. Transmission electron microscopy can provide a direct image of the grain size distribution. However, grain overlapping will lead to uncertainty and the reliability also depends on whether the thin area is a representative of the original microstructure of the entire sample. In contrast, the indirect methods based on XRD line broadening have the advantage of averaging over a much larger area of the sample and ease of sample preparation (Zhang et al. 2003). Also, XRD is of great interest as a complement to TEM. Large sampling volume, non-destructiveness and simple interpretation of XRD results are its advantages (Zhang et al. 2003; Mukherjee et al. 2004). X-ray line profile analysis has been well described and used in studying the grain size, density and arrangement of dislocations in deformed metal (Hosseini \& Kazeminezhad, 2009; Sajadi et al. 2012; Khodabakhshi et al. 2010; Khodabakhshi \& Kazeminezhad, 2011; Zhang et al. 2003; Mukherjee et al. 2004; Schafler et al. 2001; Williamson \& Hall, 1953). In this study, Grain refinement through CGP process is investigated by both methods of scanning electron microscopy and William-hall analysis on x-ray diffraction patterns. Also, mechanical properties of UFG Al sheets are investigated by tensile and micro-hardness tests.

\section{Experimental procedure and material}

The material used in this study is commercially pure aluminum sheets with dimensions of $50 \mathrm{~mm} \times 50 \mathrm{~mm} \times 1 \mathrm{~mm}$. In order to homogenization of microstructure samples were annealed at temperature of $400{ }^{\circ} \mathrm{C}$ for 2 hours and then were air-cooled. The scanning electron microscope (SEM) image of an as annealed specimen is shown in Fig. 1 and the mean grain size is about 8 micrometer.

Detail of CGP process is described elsewhere (Shin et al. 2002) as shown schematically in Fig. 2 and consists of two sequences of pressing and two sequences of flattening. The process starts by Pressing the sheet in asymmetrically grooved dies that imposes strain of $\boldsymbol{\varepsilon}$ and then imposing an extra strain of $\boldsymbol{\varepsilon}$ in reverse direction to the deformed regions of sheet by flattening the deformed sheet between a set of flat dies as schematically shown in Fig. 2, and it ends by rotating the flattened sample $180^{\circ}$ around the axis perpendicular to the plane of the sheet and repeating the sequences of pressing and flattening again. These four sequences lead to impose strain of $2 \boldsymbol{\varepsilon}$ uniformly throughout the sheet. Amount of $\boldsymbol{\varepsilon}$ differs for each die groove angle, as calculated and shown in Table 1. 


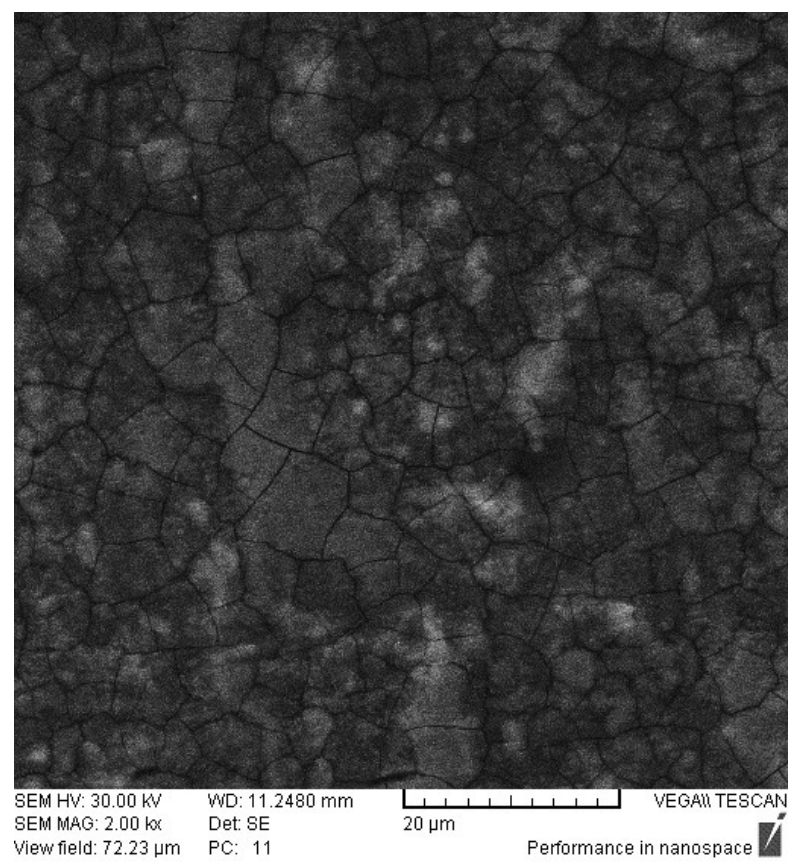

Fig. 1. SEM image of as-annealed Al
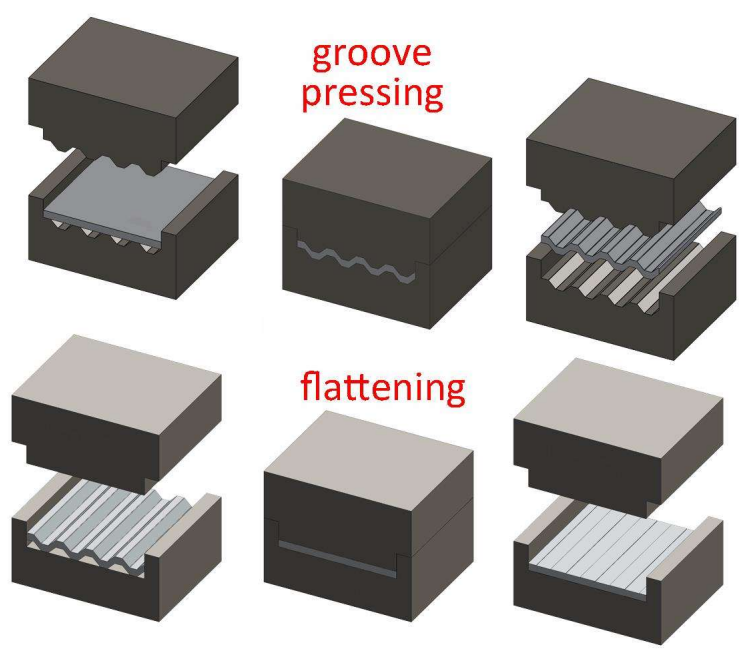

In this study, in order to find a CGP procedure that acts more effective in grain refinement and mechanical properties enhancement, three experimental procedures were defined and carried out as described below and shown in Table 1.

Procedure A. Al sheets was subjected from one to total of four passes of CGP using $45^{\circ}$ groove angle die that results in accumulated effective large strain of 4.46 at fourth pass all over the specimens.

Procedure B. Al sheets was subjected from one to total of six passes of CGP, using $\mathrm{Cu}$ sheets at top and down of the specimens and $45^{\circ}$ groove angle die that results in accumulated effective large strain of about 7 at sixth pass all over the specimens.

Procedure C. Die with $50^{\circ}$ groove angle and also $\mathrm{Cu}$ sheets at top and down of the specimens were used and effective strain of 5.52 imposed through four CGP passes.

Fig. 3 represents the dies used in procedures, position of $\mathrm{Al}$ sheet between $\mathrm{Cu}$ sheets and experimentally processed sample after the first pressing sequence.

Table 1. Effective strain calculated for one pass of CGP in two die with diffrent groove angles

\begin{tabular}{rllllll}
\hline Procedure & $\begin{array}{l}\text { groove } \\
\text { angle }(\theta)\end{array}$ & $\gamma=\tan \theta$ & $\begin{array}{l}\varepsilon_{\text {eff }}=\frac{\gamma}{\sqrt{3}} \\
\text { Shirdel et al. } \\
(2010)\end{array}$ & $\begin{array}{l}\varepsilon_{\text {eff }}^{\text {one pass }} \\
\text { (2010) }\end{array}$ & $\begin{array}{l}\text { Total strain in } \\
\text { this research }\end{array}$ & Die cavity $(\mathrm{mm})$ \\
\hline$A$ & $45^{\circ}$ & 1 & 0.58 & 1.16 & $4.46(4$ passes $)$ & $1 \mathrm{Al}$ \\
$B$ & $45^{\circ}$ & 1 & 0.58 & 1.16 & $6.69(6$ passes $)$ & $1 \mathrm{Cu}+1 \mathrm{Al}+1 \mathrm{Cu}$ \\
$C$ & $50^{\circ}$ & 1.192 & 0.69 & 1.38 & $5.52(4$ passes $)$ & $1 \mathrm{Cu}+1 \mathrm{Al}+1 \mathrm{Cu}$ \\
\hline
\end{tabular}




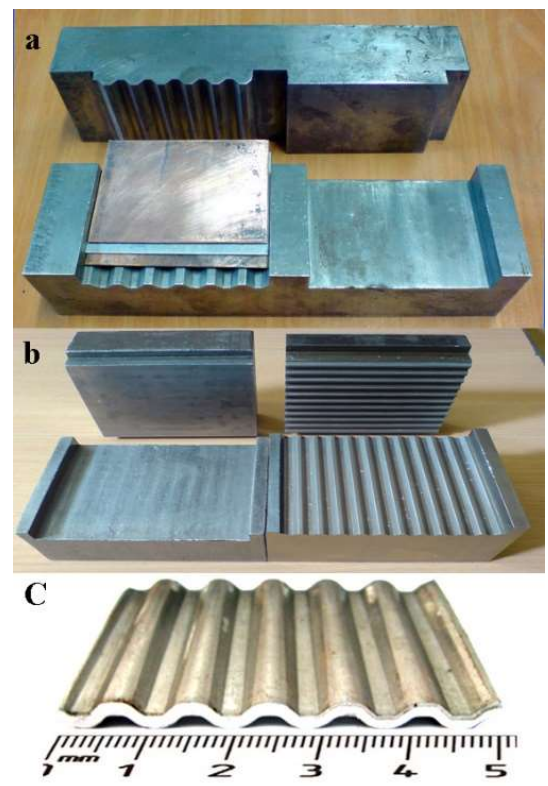

Fig. 3. (a) The position of $\mathrm{Al}$ sheet between $\mathrm{Cu}$ sheets in 45 groove angle die, (b) 50 groove angle die and (c) Shape of the Al sheet after the first sequence of CGP process

William-hall analysis on x-ray diffraction pattern is used to determine the grain size variations and scanning electron microscopy (SEM) is used for Microstructure observations and analysis. Also, in order to investigate the effect of grain refinement by CGP on mechanical properties, both standard tensile and hardness tests were carried out. Tensile tests were carried out at room temperature on the specimens with gage length of $32 \mathrm{~mm}$, width of $6 \mathrm{~mm}$ and thickness of $3 \mathrm{~mm}$ (ASTM E8M), utilizing a testing machine at a cross head speed of $0.2 \mathrm{~mm} \mathrm{~s}^{-1}$. Tensile properties of the alloy at High strength UFG condition are compared with an annealed microcrystalline (MC) condition. Also, Vickers micro-hardness tests were carried out and the reported values are the mean value of three measurements.

\section{Results and discussion}

\subsection{Microstructure evolution}

The SEM images taken from outcome sheets of each three procedures are shown in Fig. 4. It is clearly observed that CGP can refine the grains severely to submicrocrystalline range in all three procedures. Also, to tracing the variations of grain size at each pass, X-ray diffraction method is employed and Typical XRD patterns of aluminum for both as-annealed and four pass CGPed specimens are shown Fig. 5. Comparing electron microscopy observations of the previous works with the results of XRD analysis of similar works shows that both approaches determine the same range of grain size for CGPed aluminum (Hosseini \& Kazeminezhad, 2009). By using XRD line profile analysis, evolution of aluminum grain size during CGP process is investigated and shown in Fig and Table 2. As shown, during first pass of CGP, grain refinement occurs severely, and after this rapid refinement, at all procedures the rate of refining reduces. As shown in Table 2, Final grain sizes are 824, 749, and 771 for procedures A, $\mathrm{B}$ and $\mathrm{C}$, respectively. It is shown that after fourth pass in procedure $\mathrm{B}$, rate of grain refining drops to a low level and performing two extra pass has not a great effect on grain size. Therefore, it can be found that four CGP pass leads to UFG Al with a steady-state grain size. This trend of reduction in grain refinement rate is observed similarly in other methods of severe plastic deformation like accumulative roll bonding process by XING et al (Xing et al. 2002). In addition, by comparing the grain sizes at fourth pass it can be found that imposing more strain in $50^{\circ}$ groove angle die (procedure $\mathrm{C}$ ) leads to a smaller grain size than other procedures, but because of accelerating surface micro-cracking, it is not possible to perform more than four passes in procedure $\mathrm{C}$ and final grain size in procedure $\mathrm{B}$ is lesser. There is a 
good agreement in results of grain size with previous studies of ref (Hosseini \& Kazeminezhad, 2009; Lee \& Park, 2002; Sajadi et al. 2012).

Table 2. Comparing grain sizes (nanometer) at start and end of the procedures

\begin{tabular}{rllll}
\hline Procedure & Annealed & First pass & Fourth pass & Final grain size \\
\hline$A$ & 8000 & 1371 & 824 & 824 \\
$B$ & 8000 & 1375 & 806 & 749 \\
$C$ & 8000 & 1351 & 771 & 771 \\
\hline
\end{tabular}
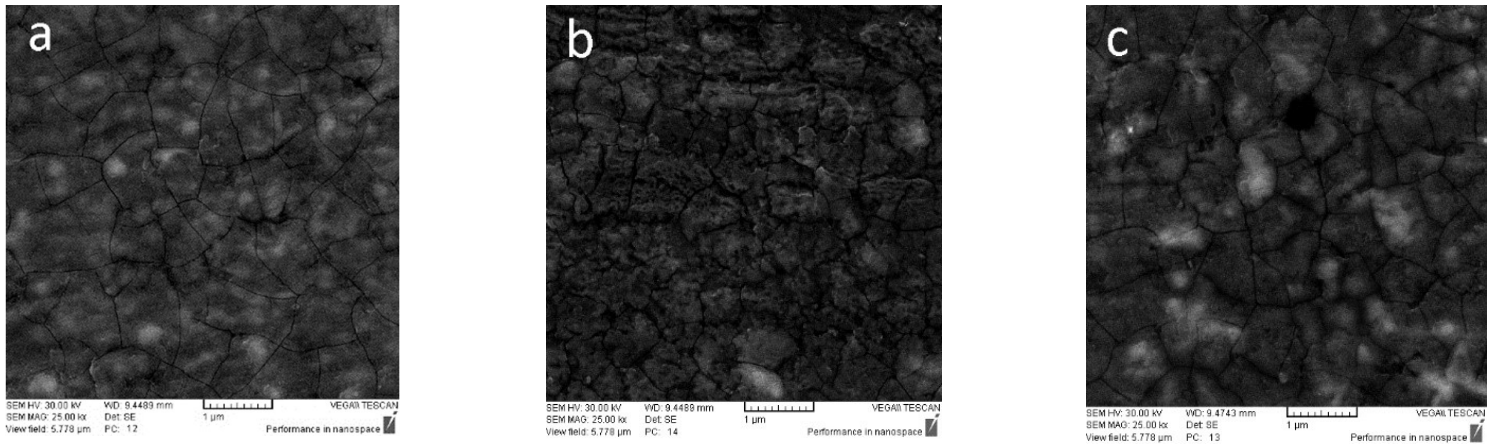

Fig. 4. SEM image of (a) a four pass CGPed sheet in procedure A, (b) a six pass CGPed specimen in procedure $\mathrm{B}$ and (c) a four pass CGPed specimen in procedure $\mathrm{C}$

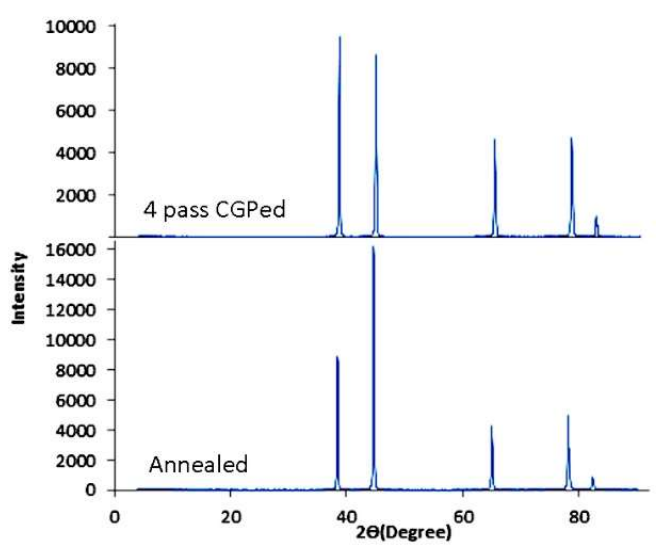

Fig. 5. Typical XRD patterns of aluminum for both annealed and CGPed samples

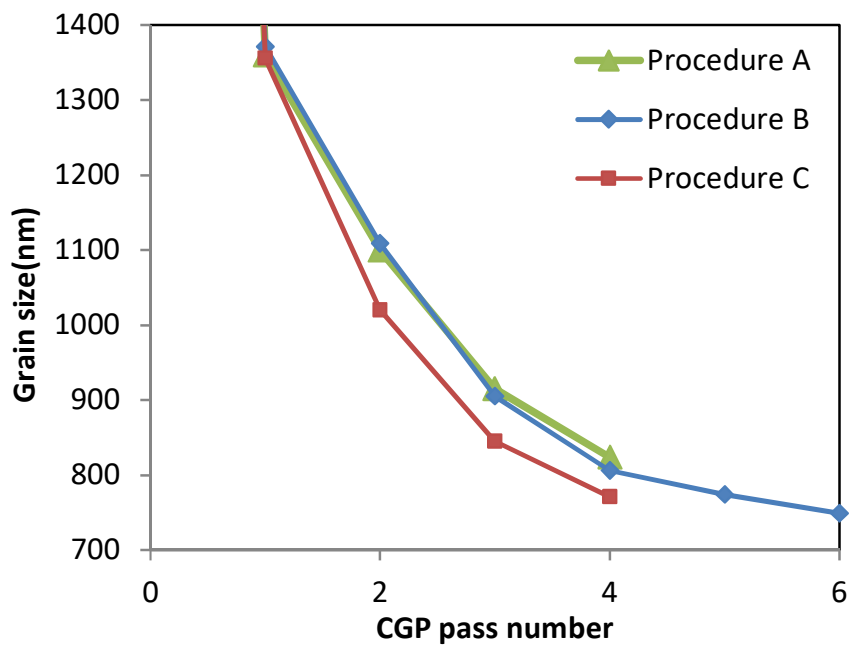

Fig. 6. The Grain size versus pass number

The trend of reduction in rate of grain refinement that has been shown similarly by XING et al (2002), can well interpret using dislocation theories. The Orowan equation has introduced as equation:

$$
\dot{\gamma}=\rho_{m} b v
$$

where $\dot{\gamma}$ is the shear strain rate, $\rho_{m}$ is dislocation density, $v$ is average dislocation glide velocity and $\mathrm{b}$ is the magnitude of the Burgers vector. In a time increment $\Delta \mathrm{t}$, a dislocation density $\rho_{m}=\dot{\rho}_{m}^{+} \Delta t$ is produced and immobilized after travelling the distance $l$. This is associated with a strain increment of $\Delta \gamma$ through work hardening. So, a relationship between the imposed strain rate and the rate of mobile dislocation 
density increasing is obtained if the Orowan equation is considered on a larger time scale as shown in Equation by Roters et al. (2000).

$$
\frac{\Delta \gamma}{\Delta t} \cong \dot{\gamma}=\dot{\rho}_{m}^{+} b l
$$

According to equation and by considering proportionality of grain size to $\rho^{-\frac{1}{2}}$ ( Hosseini et al. 2009; Estrin et al. 2008) it is expected that CGP could refine the structure in a steady rate, but three dislocation processes reduce the rate of dislocation density increasing and prohibit this uniform trend; namely, the formation of dislocation dipoles and dislocation locks as well as annihilation. F. Roters et al (2000) have explored the related equations for calculating the reduction rate $\dot{\rho}_{m}^{-}$for each three processes. The explored equations show that the rate of dislocation density reduction $\left(\dot{\rho}_{m}^{-}\right)$is proportional to the material dislocation density $\left(\rho_{m}\right)$. Since $\rho_{m}$ increases through work hardening then at large strains decrease in rate of grain refinement is expected. Therefore, trend of reducing in the rate of grain refinement by increasing in CGP passes is acceptable.

\subsection{Mechanical properties}

Results of tensile tests are shown in stress vs. strain engineering curves in Fig. 3. At a glance, early necking, a severe drop in elongation to failure and a great enhancement in both yield stress (YS) and ultra-tensile strength (UTS) in all procedures is clear. Generally, it can be said that nanocrystalline materials exhibit high amount of strength and tend to exhibit early plastic instability by necking and much reduced ductility, due in part to a low work hardening rate, low $\mathrm{n}$ in Hollomon's relation, (Dieter \& Bacon, 1986; Meyers et al. 2006) and also due to a reduced ability of the materials to accommodate the progression of cracks by extensive plastic deformation (Meyers et al. 2006). This behavior necessitates higher applied stress to cause further deformation resulting in higher strength. The drastic drop in ductility can be attributed to the loss of strain hardening ability of severe plastically deformed sheets. The decreased strain hardening ability of severe plastically deformed materials is mainly attributed to the absence of dislocation tangling which is responsible for extensive strain hardening ability and faster dislocation spreading kinetics (Kumar \& Raghu, 2013; Park \& Shin, 2002). Improvement in ductility characteristics of nanocrystalline materials produced by various methods of severe plastic deformation without significant loss in strength is an important issue and many recent efforts have been made to find strategies for improving ductility of nanocrystalline materials (Ma, E. 2006; Zherebtsov et al. 2012; Zhao et al. 2008; Zhao et al. 2010).

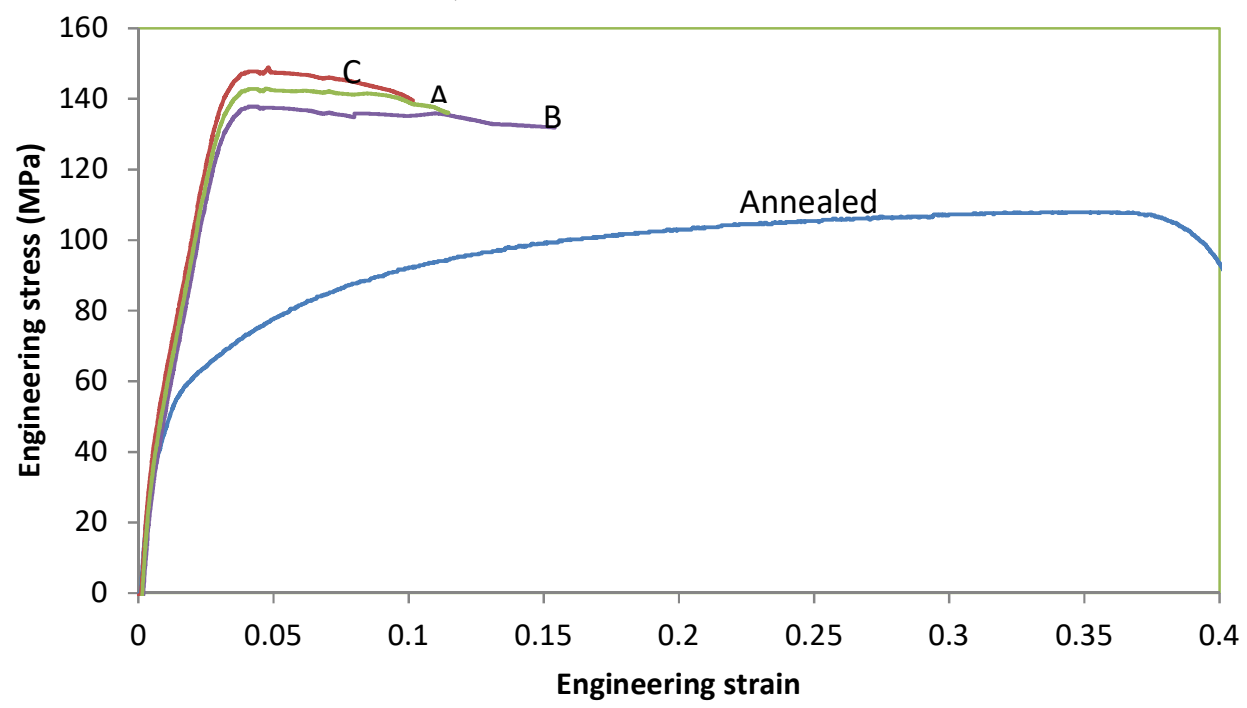

Fig. 3. Engineering stress-strain curve of annealed sheets and CGPed sheets in procedure A 
The trend of increasing in strength due to grain refinement and work hardening is well known and concurs with Hall-Petch relation, but as shown in Fig there is an unusual dropping in amount of both yield stress and UTS at sixth pass for procedure B that needs anymore discussion. Some previous researches corroborate this phenomenon (Shin et al. 2002; Hosseini \& Kazeminezhad, 2009; Kirishnaiah et al. 2005; Sajadi et al. 2012) but the distinction in this study is promoting this phenomenon from fourth pass to sixth pass in $45^{\circ}$ groove angle die. One of the mechanisms that are mentioned in previous papers for explaining this phenomenon is micro-cracking (Kumar \& Raghu, 2013; Hosseini \& Kazeminezhad, 2009; Borhani \& Djavanroodi, 2012; Sajadi et al. 2012; Khodabakhshi et al. 2010). Since during CGP of sheets cracks initiate from surface, sheets surfaces condition is a vital parameter for continuation of deformation. Friction between rigid die surface and Al sheets causes nucleation and growth of microcracks at surface of the Al sheets and limits both the number of performed passes of CGP by growth of micro-cracks and mechanical properties of successive CGPed sheets. Therefore, using Cu deformable sheets at top and down of the specimen instead of rigid die surface as a lubricant, is the main reason of the success of promoting the micro-cracks to sixth pass in this research.
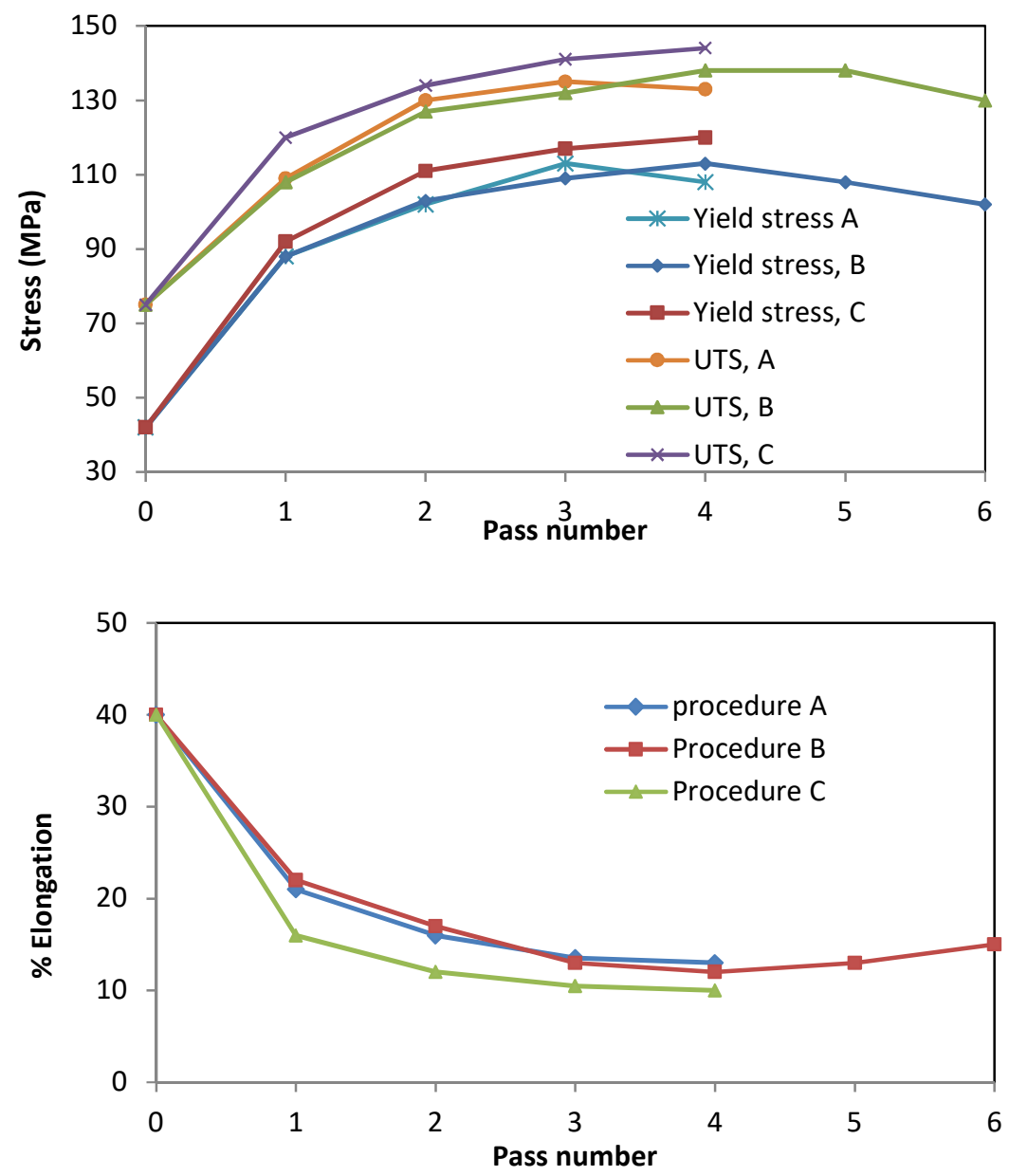

Fig. 8. Variation of (a) strength and (b) elongation through CGP in various procedures

In some previous successive work (Hosseini \& Kazeminezhad, 2009) by removing the exterior layers of sheets and repeating the similar tensile tests, it is shown that micro cracking is not the sole mechanism for strength dropping and the associate mechanism is "flow softening" of severely deformed sheets and some other investigators have confirmed it (Kumar \& Raghu, 2013; Hosseini \& Kazeminezhad, 2009; Khodabakhshi et al. 2010). Restoration of strain hardening ability due to the dominance of dislocation annihilation occurs during deformation at higher strains (Kumar \& Raghu, 2013; Kumar \& Raghu, 2011) 
and could have resulted in the drop in strengths (YS and UTS). Since micro-cracking has negligible effect on hardness magnitudes (Hosseini \& Kazeminezhad, 2009) the results of Vickers micro hardness tests can be used for evaluating the presence of flow softening mechanism in strength reduction of CGPed sheets. Vickers micro hardness tests were carried out at room temperature and mean values of three measurements are reported in each point in Fig. As can be seen, there is an intensive increase in amount of hardness after first pass and at the next passes rate of increase in hardness reduces and finally there is a little drop at sixth pass hardness value. This significant increase in hardness upon first pass concurs with observation of higher grain refinement rates and severe increase in strength that discussed earlier. Drop in amount of hardness at final pass proves the presence of an effective mechanism like "flow softening". Because of absence of micro-cracking effect on hardness, the final drop in hardness values in sixth pass is not as intense as that of strength. Similar trend has been reported earlier during groove pressing of pure Al sheets (Hosseini \& Kazeminezhad, 2009; Kirishnaiah et al. 2005).

It should be considered that as can be seen, procedure $\mathrm{C}$ leads to a sub-microcrystalline sheets with higher hardness values relative to that of procedure $\mathrm{A}$ and $\mathrm{B}$, and there is not any drop in hardness values of processed sheets in procedure C. Higher hardness can be mainly attributed to higher imposed strain and higher amount of work hardening at each pass that leads to finer grains in procedure $\mathrm{C}$ (as shown in Fig). In addition, it should be considered that higher groove angle in procedure $\mathrm{C}$, leads to increase stresses in the specimen at the corner of the teeth and earlier micro-cracking (Sajadi et al. 2012). Hence, higher grooved angle does not permit conducting extra four passes of CGP and at the subsequent passes Dominance of micro-cracking mechanism leads to failure. In other hand, since dominance of dislocation annihilation and flow softening mechanism occurs at higher strains (Kumar \& Raghu, 2011), flow softening mechanism has less effect on mechanical properties of sheets that performed in procedure C. Similar trends were reported by previous investigators (Kumar \& Raghu. 2013; Sajadi et al. 2012).

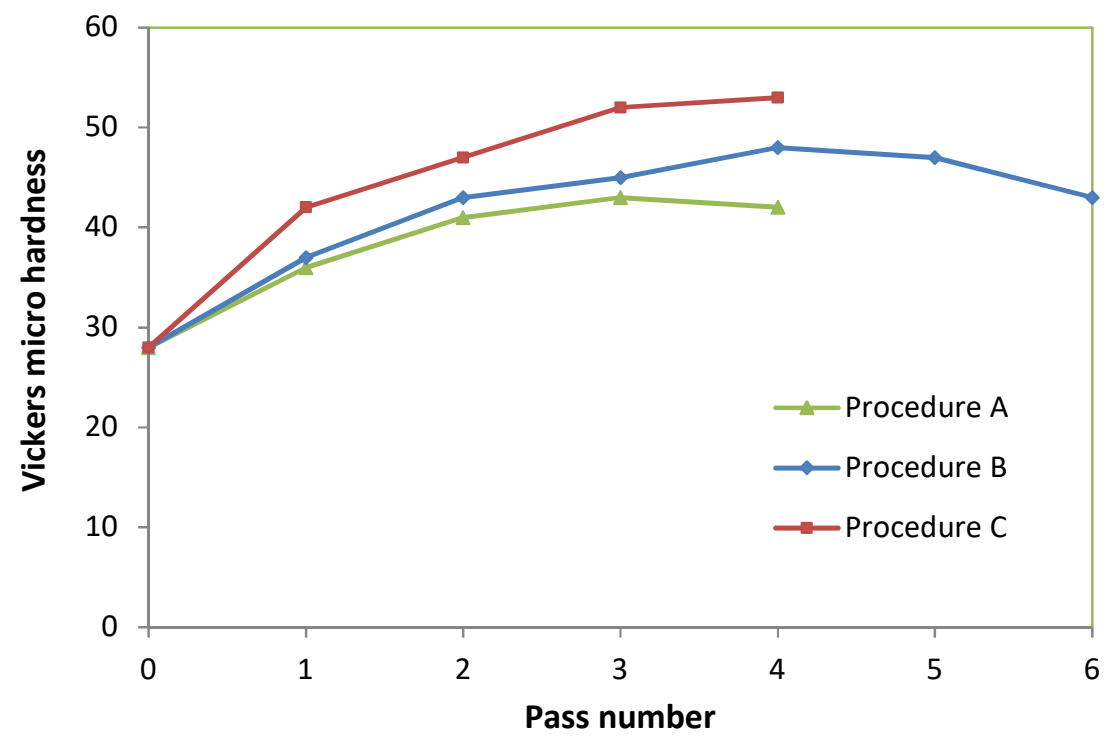

Fig. 9. Vickers micro-hardness versus pass number

Also, to investigate the hardness distribution and homogeneity of deformation in the longitudinal direction of the sheet totals of seven hardness measurements tests carried out along the parallel lines and the results for CGPed sheets of both procedures are shown in Fig. 

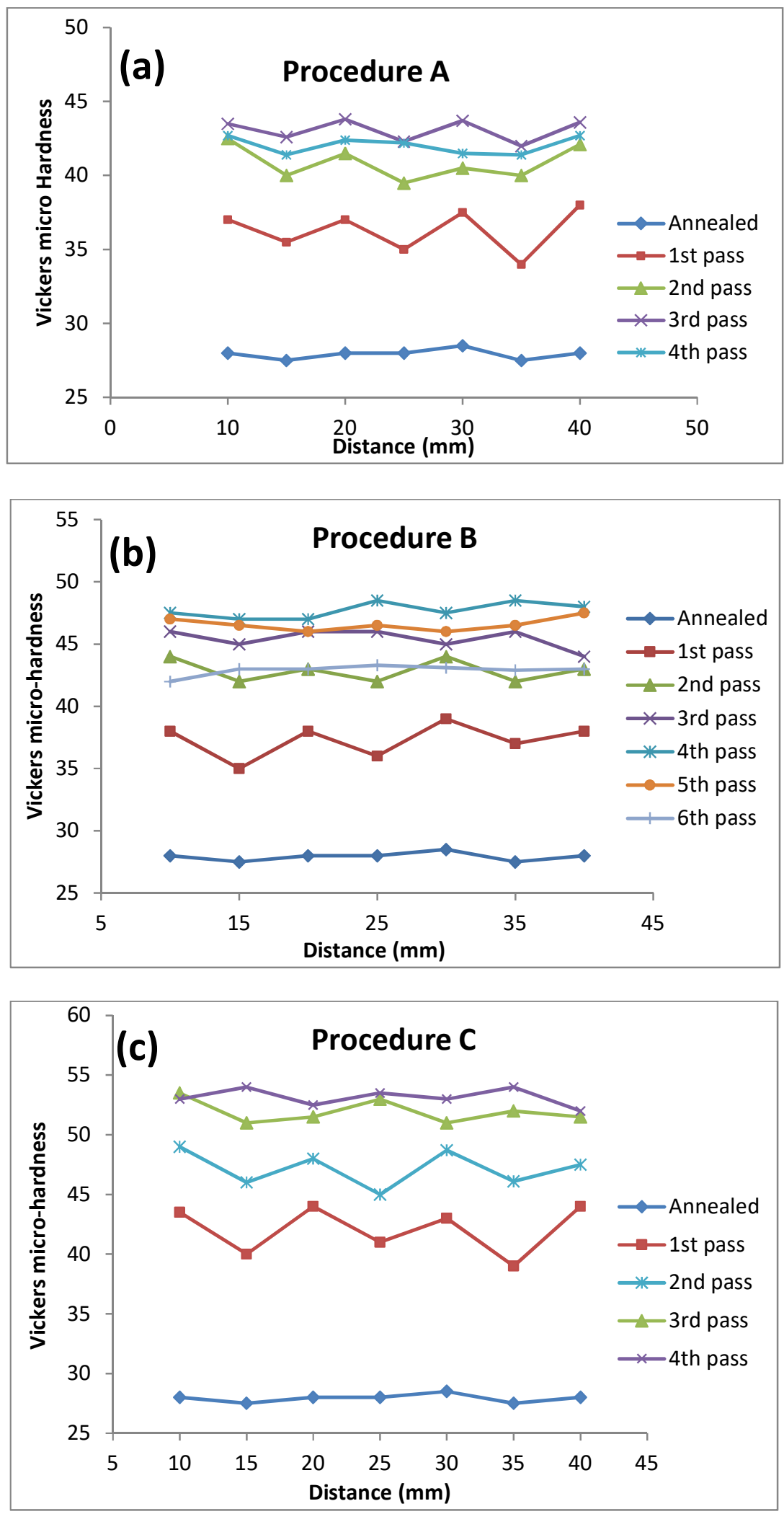

Fig. 10. Variation of hardness at longitudinal direction of CGPed sheets in (a) procedure A. (b) procedure $\mathrm{B}$ and $(\mathrm{c})$ procedure $\mathrm{C}$ 
In order to investigate the uniformity of hardness throughout the CGPed sheets the inhomogeneity factor (I.F.) is used. The I.F. can be calculated by equation as below (Rafizadeh et al. 2009):

$$
I . F .=\frac{\sqrt{\sum_{i=1}^{i=n}(H i-\bar{H})^{2} /(n-1)}}{\bar{H}} \times 100
$$

where $n$ is the number of hardness measurements on each sheet, $H_{i}$ is the hardness value of i-th measurement, and $\bar{H}$ is the mean hardness value. In general, less I.F. value indicates higher homogeneity of mechanical properties (Rafizadeh et al. 2009). Fig shows the I.F. of CGPed sheets versus pass number for various procedures. As can be seen, the I.F. of one pass CGPed specimen is increased severely compared with that of as annealed one. For CGPed sheets, the I.F. is decreased with increasing the pass number indicating increase of strain homogeneity. As Comparing I.F. values of two procedures, it is found that procedure A leads to a more homogenous deformation and hardness distribution.

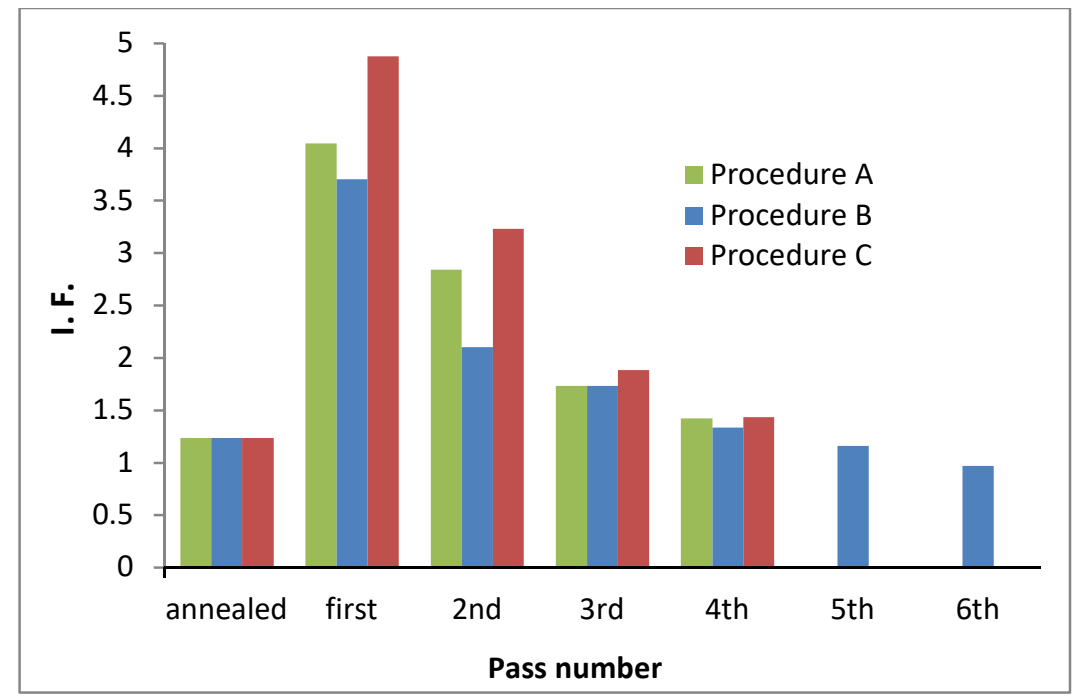

Fig. 11. I.F. of CGPed sheets versus pass numbers at various procedures

\section{Conclusions}

In this research, achieving submicrocrystalline structure in a commercially pure Al is investigated; using various experimental procedures of severe plastic deformation method named "constrained groove pressing" and the findings can be summarized as follows:

1. Microstructural observations indicate that grain refinement occurs severely upon first pass of CGP and after that, the rate of refining reduces. This drop in rate of grain refinement can well be interpreted using dislocation theory.

2. Early plastic instability by necking and much reduced ductility, due in part to a low work hardening rate (low $\mathrm{n}$ in Hollomon's relation) was observed in results of tensile tests of CGPed sheets.

3. Friction between rigid die surfaces and Al sheet causes nucleation and growth of micro-cracks at surfaces of the Al sheet and can resulting to drop in strength and hardness of CGPed sheets. This phenomenon can postpone by using $\mathrm{Cu}$ deformable sheets at top and bottom of specimens.

4. Restoration of strain hardening ability due to the dominance of dislocation annihilation occurs during deformation at higher strains and can results in the drop in strengths (both YS and UTS).

5. Higher imposed strain in $50^{\circ}$ groove angle die does not permit conducting extra four passes of CGP and at the final passes dominance of micro-cracking mechanism leads to failure of the 
specimen. Since dominance of dislocation annihilation and flow softening mechanism occurs at higher strains, flow softening mechanism has less effect on mechanical properties of sheets processed in procedure $\mathrm{C}$.

6. Using $\mathrm{Cu}$ sheets at top and bottom of $\mathrm{Al}$ sheet leads to increasing homogeneity of deformation and uniform distribution of mechanical properties as observed by lesser I.F. values in $45^{\circ}$ groove angle die.

\section{References}

Alexander, D. J. (2007). New methods for severe plastic deformation processing. Journal of Materials Engineering and Performance, 16(3), 360-374.

Azushima, A., Kopp, R., Korhonen, A., Yang, D. Y., Micari, F., Lahoti, G. D., ... \& Yanagida, A. (2008). Severe plastic deformation (SPD) processes for metals. CIRP Annals, 57(2), 716-735.

Borhani, M., \& Djavanroodi, F. (2012). Rubber pad-constrained groove pressing process: Experimental and finite element investigation. Materials Science and Engineering: A, 546, 1-7

Dieter, G. E., \& Bacon, D. J. (1986). Mechanical metallurgy (Vol. 3). New York: McGraw-hill.

Dong, X. L., Yun, B., \& Ma, Z. H. (2011). Grain refinement in constrained groove pressing of 7050 Aluminum alloy. In Advanced Materials Research (Vol. 189, pp. 2823-2826). Trans Tech Publications.

Estrin, Y., Molotnikov, A., Davies, C. H. J., \& Lapovok, R. (2008). Strain gradient plasticity modelling of high-pressure torsion. Journal of the Mechanics and Physics of Solids, 56(4), 1186-1202

Hosseini, E., Kazeminezhad, M., Mani, A., \& Rafizadeh, E. (2009). On the evolution of flow stress during constrained groove pressing of pure copper sheet. Computational Materials Science, 45(4), 855-859.

Hosseini, E., \& Kazeminezhad, M. (2009). Retracted: Nanostructure and mechanical properties of 0-7 strained aluminum by CGP: XRD, TEM and tensile test.

Huang, J., Zhu, Y. T., Alexander, D. J., Liao, X., Lowe, T. C., \& Asaro, R. J. (2004). Development of repetitive corrugation and straightening. Materials Science and Engineering: A, 371(1-2), 35-39.

Khodabakhshi, F., Kazeminezhad, M., \& Kokabi, A. H. (2010). Constrained groove pressing of low carbon steel: Nano-structure and mechanical properties. Materials Science and Engineering: A, 527(16-17), 4043-4049.

Khodabakhshi, F., \& Kazeminezhad, M. (2011). The effect of constrained groove pressing on grain size, dislocation density and electrical resistivity of low carbon steel. Materials \& Design, 32(6), 32803286.

Krishnaiah, A., Chakkingal, U., \& Venugopal, P. (2005). Production of ultrafine grain sizes in aluminium sheets by severe plastic deformation using the technique of groove pressing. Scripta Materialia, 52(12), 1229-1233.

Kumar, S. S., \& Raghu, T. (2011). Tensile behaviour and strain hardening characteristics of constrained groove pressed nickel sheets. Materials \& Design, 32(8-9), 4650-4657.

Kumar, S. S., \& Raghu, T. (2013). Mechanical behaviour and microstructural evolution of constrained groove pressed nickel sheets. Journal of Materials Processing Technology, 213(2), 214-220.

Ma, E. (2006). Eight routes to improve the tensile ductility of bulk nanostructured metals and alloys. Jom, 58(4), 49-53.

Meyers, M. A., Mishra, A., \& Benson, D. J. (2006). Mechanical properties of nanocrystalline materials. Progress in Materials Science, 51(4), 427-556

Mukherjee, P., Sarkar, A., Barat, P., Bandyopadhyay, S. K., Sen, P., Chattopadhyay, S. K., ... \& Mitra, M. K. (2004). Deformation characteristics of rolled zirconium alloys: a study by X-ray diffraction line profile analysis. Acta materialia, 52(19), 5687-5696.

Park, K. T., \& Shin, D. H. (2002). Microstructural interpretation of negligible strain-hardening behavior of submicrometer-grained low-carbon steel during tensile deformation. Metallurgical and Materials Transactions A, 33(3), 705-70 
Rafizadeh, E., Mani, A., \& Kazeminezhad, M. (2009). The effects of intermediate and post-annealing phenomena on the mechanical properties and microstructure of constrained groove pressed copper sheet. Materials Science and Engineering: A, 515(1-2), 162-168.

Roters, F., Raabe, D., \& Gottstein, G. (2000). Work hardening in heterogeneous alloys-a microstructural approach based on three internal state variables. Acta materialia, 48(17), 4181-4189.

Saito, Y., Utsunomiya, H., Tsuji, N., \& Sakai, T. (1999). Novel ultra-high straining process for bulk materials - development of the accumulative roll-bonding (ARB) process. Acta materialia, 47(2), 579-583

Schafler, E., Zehetbauer, M., \& Ungar, T. (2001). Measurement of screw and edge dislocation density by means of X-ray Bragg profile analysis. Materials Science and Engineering: A, 319, 220-223.

Shin, D. H., Park, J. J., Kim, Y. S., \& Park, K. T. (2002). Constrained groove pressing and its application to grain refinement of aluminum. materials Science and Engineering: A, 328(1-2), 98-103.

Valiev, R. Z., Estrin, Y., Horita, Z., Langdon, T. G., Zechetbauer, M. J., \& Zhu, Y. T. (2006). Producing bulk ultrafine-grained materials by severe plastic deformation. Jom, 58(4), 33-39.

Williamson, G. K., \& Hall, W. H. (1953). X-ray line broadening from filed aluminium and wolfram. Acta Metallurgica, 1(1), 22-31

Xing, Z. P., Kang, S. B., \& Kim, H. W. (2002). Structure and properties of AA3003 alloy produced by accumulative roll bonding process. Journal of Materials Science, 37(4), 717-722.

Zhang, Z., Zhou, F., \& Lavernia, E. J. (2003). On the analysis of grain size in bulk nanocrystalline materials via X-ray diffraction. Metallurgical and Materials Transactions A, 34(6), 1349-1355.

Zhao, Y., Topping, T., Bingert, J. F., Thornton, J. J., Dangelewicz, A. M., Li, Y., ... \& Lavernia, E. J. (2008). High tensile ductility and strength in bulk nanostructured nickel. Advanced Materials, 20(16), 3028-3033

Zhao, Y., Zhu, Y., \& Lavernia, E. J. (2010). Strategies for improving tensile ductility of bulk nanostructured materials. Advanced Engineering Materials, 12(8), 769-778.

Zherebtsov, S., Kudryavtsev, E., Kostjuchenko, S., Malysheva, S., \& Salishchev, G. (2012). Strength and ductility-related properties of ultrafine grained two-phase titanium alloy produced by warm multiaxial forging. Materials Science and Engineering: A, 536, 190-196.

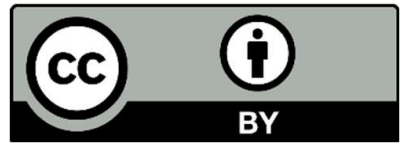

(C) 2020 by the authors; licensee Growing Science, Canada. This is an open access article distributed under the terms and conditions of the Creative Commons Attribution (CC-BY) license (http://creativecommons.org/licenses/by/4.0/). 